\title{
A Imagem dos Destinos Turísticos: a cidade de São Paulo sob o olhar de jovens do Rio de Janeiro
}

\section{Image Of Tourist Destinations: The City of São Paulo under the Standpoint of Young of Rio de Janeiro}

Aline Alves Figueirêdo ${ }^{1}$

Verônica Feder Mayer ${ }^{2}$

\begin{abstract}
Resumo
Este trabalho analisa a imagem do destino turístico cidade de São Paulo a partir da visão do público jovem da Região Metropolitana do Rio de Janeiro e faz uma relação entre a imagem percebida pelo público e a intenção em visitar o destino estudado. Para atingir os objetivos do trabalho, foram conduzidos dois estudos por meio de uma combinação de metodologias estruturadas e não-estruturadas. $\mathrm{O}$ estudo 1 confirmou que há um conflito entre a imagem que a cidade visa transmitir e a que é percebida. O estudo 2, por sua vez, gerou a lista de atributos que compõem a imagem do destino. Verifica-se que a marca da cidade está mal posicionada perante o público pesquisado, com características presentes em outras metrópoles, o que acaba por não lhe conferir um diferencial competitivo. Foram encontrados ainda baixos níveis de interesse e intenção em visitar a cidade.
\end{abstract}

Palavras-chave: comportamento do consumidor; imagem; cidade de São Paulo.

\begin{abstract}
This paper analyzes the image of São Paulo city like a tourist destination from the standpoint of young people in the metropolitan region of Rio de Janeiro and makes a relationship between the perceived image by the public and the intention to visit the destination area. To achieve the objectives of the study, two researches were conducted using a combination of structured and non-structured methodologies. The study 1 confirmed that there is a conflict between the promoted image and the one that is perceived. The study 2, in turn, generated a list of attributes that composes the destination image. It is verified the city brand is bad positioned in public mind, with features present in other cities that consequently do not give it a competitive advantage. It was also found low levels of interest and intention in visiting the city.

Keywords: consumer behavior; image; São Paulo city.

1 Graduada em Turismo pela Universidade Federal Fluminense. Mestranda em Administração pelo Coppead/UFRJ. Email: alinealvesf@gmail.com.

2 Doutora em Administração pelo Coppead/UFRJ com extenção na University of Illinois at Urbana-Champaign; CPCL pela Harvard Business School. Professora Adjunta da Universidade Federal Fluminense - Faculdade de Administração, Ciências Contábeis e Turismo. EMAIL: vmayer@gmail.com.
\end{abstract}




\section{Introdução}

O turismo, ao longo dos anos, ganha maiores proporções em todo mundo e passa a receber atenção especial do governo de países, estados e cidades que possuem representativo fluxo turístico ou que apresentam potencial para a prática da atividade. $\mathrm{O}$ seu desenvolvimento acarreta um aumento da competitividade, a qual leva a uma disputa entre destinos por mercados consumidores. O marketing, então, se torna em "um assunto de vital importância [...] pois representa a principal influência do gerenciamento que pode ser aplicada ao tamanho e comportamento deste importante mercado global" (MIDDLETON, 2002, p. 4). Nesse contexto, a imagem dos destinos e seu papel no processo de escolha de um destino são essenciais para os planejadores do turismo.

O destino turístico escolhido como objeto de estudo do presente trabalho foi a cidade de São Paulo. Segundo informações obtidas junto à Prefeitura da cidade de São Paulo (2006) e à Empresa de Turismo e Eventos da Cidade de São Paulo - SPTURIS (2006), a cidade possui diversos equipamentos turísticos ou de apoio ao turismo, além de 19 bens tombados pelo IPHAN.

Tomando conhecimento dos dados sobre a infraestrutura turística da cidade de São Paulo, houve o interesse em estudar a imagem desse município, como elemento para seu sucesso na atividade turística.

O presente trabalho visa identificar a formação da imagem do destino turístico cidade de São Paulo a partir da visão do público jovem da Região Metropolitana do Rio de Janeiro e verificar a influência potencial da imagem percebida pelo público-alvo no referido destino turístico. A partir dos resultados encontrados, pretende-se fornecer insights para os responsáveis por gerenciar o turismo na cidade.

Para atingir tais objetivos, foi escolhida como público-alvo a região metropolitana do Rio de Janeiro, que compreende as cidades de Belford Roxo, Duque de Caxias, Guapimirim, Itaboraí, Japeri, Magé, Mesquita, Nilópolis, Niterói, Nova Iguaçu, Paracambi, Queimados, Rio de Janeiro, São Gonçalo, São João de Meriti, Seropédica e Tanguá (Instituto Brasileiro de Geografia e Estatística - IBGE, 2007). A região forma a segunda maior metrópole do Brasil e 
sua principal cidade, o Rio de Janeiro, está apenas a $429 \mathrm{~km}$ da cidade de São Paulo. Além disso, ostenta um Produto Interno Bruto de $\mathrm{R} \$ 172.563 .073 .000$, constituindo o segundo maior pólo de riqueza nacional (IBGE, 2007).

Esse trabalho limita-se a investigar a imagem da cidade de São Paulo a partir da decomposição de seus atributos. Porém, o estudo da imagem pode envolver diversas interpretações e metodologias usadas a fim de conhecer melhor esse importante elemento do planejamento da atividade turística nos destinos. Pretende-se também contribuir para o aumento da literatura existente sobre avaliação da imagem de destinos turísticos no Brasil.

\section{Marca e Imagem}

Kotler e Armstrong (1998, p. 45) definem marca como "um nome, termo, sinal, símbolo ou a combinação desses elementos, cuja finalidade é a de identificar produtos ou serviços de um vendedor ou grupo de vendedores e diferenciá-los de seus competidores". Para os autores, marcas representam uma promessa de valor e podem incitar crenças, evocar emoções e induzir comportamentos. Elas podem adicionar ou subtrair o valor percebido de um produto.

Keller (1993) apontou dois estágios do desenvolvimento do valor da marca, que são nível de consciência e nível de imagem. O nível de consciência é simplesmente descrito e medido por reconhecimento e lembrança. O nível de imagem, contudo, não pode ser avaliado apenas pela medição de seus atributos, mas deve incluir também uma medição das percepções dos consumidores dos valores e benefícios alcançados ao usar a marca (AAKER, 1997; KELLER, 1993).

É pela marca que tipicamente se comunica a imagem. Com relação à imagem de um destino, Kotler e Gertner (2002, p. 251) a definem como:

o conjunto de crenças e impressões que as pessoas possuem sobre lugares. Imagens representam a simplificação de uma grande quantidade de associações e informações relacionadas a um lugar. Elas são um produto da 
mente que tenta processar informações essenciais de uma grande quantidade de dados sobre um lugar.

Ao estudar a imagem, Richardson e Cohen (1993) ressaltam a importância das proposições únicas de venda na divulgação da marca de um destino, visto que são proposições com informações suficientemente substanciais sobre produtos para serem verdadeiras ou falsas que informam os consumidores sobre benefícios genuínos do produto.

Baloglu (1999) apresenta um modelo geral para a formação da imagem de um destino, baseado principalmente em fatores pessoais e fatores de estímulo (Figura 1).

\begin{tabular}{|c|c|c|}
\hline $\begin{array}{l}\text { Fatores Pessoais } \\
\text { - } \quad \text { Psicológicos } \\
\text { - Valores } \\
\text { - Motivações } \\
\text { - Personalidade } \\
\text { - } \text { Social } \\
\text { - Idade } \\
\text { - Educação } \\
\text { - Estado Civil } \\
\text { - Outros }\end{array}$ & $\begin{array}{l}\text { Imagem do Destino } \\
\text { - } \quad \text { Percebida/ } \\
\text { Cognitiva } \\
\text { - } \quad \text { Afetiva } \\
\text { - } \\
\text { Global }\end{array}$ & $\begin{array}{l}\text { Fatores de Estímulo } \\
\text { - } \quad \text { Fontes de } \\
\text { Informação } \\
\text { - Quantidade } \\
\text { - Tipo } \\
\text { - } \quad \text { Experiência } \\
\text { anterior } \\
\text { - } \quad \text { Distribuição }\end{array}$ \\
\hline
\end{tabular}

Figura 1 - Modelo geral de formação da imagem de um destino

Na literatura internacional, o tema "imagem de destinos turísticos” já vem sendo abordado há décadas. Alguns dos trabalhos mais importantes são os de Woodside e Lysonski (1989), Um e Crompton (1990), Echtner e Ritchie (1991), e, mais recentemente os de Rezende-Parker, Morrison e Ismail (2003), de Beerli e Martín (2004), de O’Leary e Deegan (2005) e de Lee, Cai e O'Leary (2005). Em âmbito nacional, o mesmo tema passou a ser tratado mais recentemente, com destaque para os estudos de Ruschmann (2001), Zottis (2004), Ituassu e Oliveira (2004), Pérez-Nebra (2005), Oliveira (2006) e Leal (2006). 


\section{Metodologia}

Para o presente trabalho foram feitos dois estudos de cunho exploratório. O objetivo de uma pesquisa exploratória é procurar padrões, ideias ou hipóteses ao invés de testar uma hipótese já conhecida (COLLIS; HUSSEY, 2005).

A metodologia escolhida teve como objetivo gerar a lista de atributos que compõem a imagem da cidade de São Paulo. Para Echtner e Ritchie (2003), ao examinar as metodologias usadas para medir a imagem do destino, a maioria das pesquisas sobre o assunto prioriza a formação da imagem em termos de listas de atributos, sendo menos comum a mensuração por meio de impressões holísticas.

No estudo 1, foi feita uma pesquisa qualitativa constituída de 2 etapas, a saber: análise de conteúdo sobre a cidade de São Paulo e free elicitation. Esse estudo teve o objetivo de comparar o que a imagem da cidade de São Paulo visa transmitir ao seu público-alvo, por meio da análise de conteúdo, com o que a população estudada pensa a respeito do destino por meio da free elicitation. Baseado no modelo de Baloglu (1999), o estudo 1 faz um recorte na teoria a fim de avaliar as fontes de informação como fatores de estímulo que contribuem para a percepção da imagem de um destino.

Para a análise de conteúdo foram utilizados folhetos e sites oficiais da Prefeitura de São Paulo e pacotes de operadoras que vendem o destino São Paulo. Para Oleary e Deegan (2005), a análise de conteúdo de informação escrita, como guias de viagem, ou informação visual, incluindo imagens em panfletos de viagens, pode proporcionar uma grande quantidade de informação sobre imagens projetadas por um destino turístico. Como foram utilizados folhetos e sites oficiais da Prefeitura de São Paulo, é possível interpretar que as fontes de informação utilizadas são aquelas que estão sob controle do órgão que gerencia a imagem da cidade. A free elicitation, um procedimento qualitativo que consiste em uma associação de palavras, por sua vez, averiguou os atributos da imagem da cidade de São Paulo mais importantes para uma amostra de 64 jovens moradores da região metropolitana do Rio de Janeiro, dentro da faixa etária de 20 a 29 anos. A free elicitation tem sido amplamente usada no campo da pesquisa de mercado (OLEARY E DEEGAN, 2005). 
No estudo de Oleary e Deegan (2005), os autores perguntaram a uma amostra aleatória de visitantes franceses, no setor de saída do aeroporto de Dublin em outubro de 1997, quais eram as três primeiras palavras ou expressões que vinham à mente quando eles pensavam na Irlanda. Os autores não explicaram o critério usado para determinar o tamanho da amostra. A técnica de free elicitation permitiu que os participantes descrevessem o destino sem inferências predeterminadas pelo pesquisador. A obtenção desses atributos foi uma tentativa de ganhar uma representação mais precisa da imagem da Irlanda para o turista francês.

Para a elaboração deste trabalho foi feita uma free elicitation de forma semelhante. Foi feita a pergunta "Quais são as três primeiras palavras ou expressões que vêm à sua mente quando você pensa na cidade de São Paulo?” para 64 moradores da Região Metropolitana do Rio de Janeiro durante o período de 2 de setembro a 27 de setembro de 2007. Os respondentes estão dentro da faixa etária de 20 a 29 anos e possuem ensino superior incompleto. A pergunta foi enviada por e-mail. O tamanho da amostra se assemelha a que foi utilizada por Oleary e Deegan (2005). Foi utilizada uma amostra de conveniência, não probabilística, escolhida pela facilidade de acesso aos participantes, o que não faz com que os componentes da população sejam proporcionalmente representados, como acontece em uma amostragem aleatória.

Foi tomada a decisão de utilizar todos os itens encontrados na free elicitation na elaboração da lista de atributos da imagem da cidade de São Paulo no estudo 2.

O estudo 2 utilizou principalmente métodos quantitativos e foi elaborado com os dados do estudo 1. Por meio de uma articulação entre os resultados da análise de conteúdo e da free elicitation, somados a uma revisão de literatura sobre a imagem dos destinos turísticos, surgiu a lista de atributos da imagem da cidade de São Paulo a partir da visão de moradores jovens da Região Metropolitana do Rio de Janeiro.

No estudo 2 foi utilizada a técnica de aplicação de questionários elaborados por meio de uma combinação de metodologias estruturadas e não estruturadas. De acordo com Etchner e Ritchie (1991), metodologias estruturadas são focadas nos atributos da imagem, ou seja, forçam o respondente a pensar na imagem a partir dos atributos especificados em uma determinada escala. Embora as impressões holísticas possam ser relacionadas pelo 
respondente, uma vez completados os itens da escala, não há oportunidade direta para que essas impressões sejam descritas.

Segundo as autoras supracitadas, metodologias não estruturadas são uma alternativa na medição de uma imagem. Os atributos da imagem não estão especificados, o que permite que as impressões de um destino sejam descritas mais livremente.

O questionário do estudo 2 foi dividido em três partes. A primeira parte buscou dados sociodemográficos do público participante. A segunda parte constituiu-se de uma pergunta aberta sobre atrativos turísticos na cidade de São Paulo e apresentou a lista de atributos ou imagens relacionados à cidade de São Paulo. Os participantes classificaram suas percepções dos atributos de São Paulo em uma escala de cinco pontos de Likert, de plena discordância a plena concordância. A terceira parte do questionário incluiu questões que consideraram o interesse e a intenção dos respondentes em visitar a cidade de São Paulo no futuro.

O questionário pode ser respondido por usuários da rede mundial de computadores através do site www.uff.br/intretere/pesquisa.html durante o período de 20 de outubro de 2007 a 10 de janeiro de 2008. Os entrevistados foram contatados, em sua maioria, pelo site de relacionamentos denominado Orkut. Como será mostrado na sessão de resultados da pesquisa, os questionários do estudo 2 foram predominantemente respondidos por pessoas de 15 a 29 anos. Sendo assim, consideramos uma visão predominante de respostas de uma população jovem. Foram abordados participantes de comunidades virtuais das cidades da Região Metropolitana do Rio de Janeiro. Houve ainda casos em que os entrevistados receberam o questionário diretamente via e-mail. Uma mensagem foi postada nas comunidades escolhidas, solicitando a participação na pesquisa.

Para a coleta de dados do estudo 2 também foi utilizada uma amostra de conveniência, nãoprobabilística, escolhida pela facilidade de acesso aos respondentes. Um total de 217 respostas foi recebido. No questionário, foram avaliados 33 atributos da imagem de São Paulo por meio de uma análise fatorial. De acordo com Rezende-Parker, Morrison e Esmail (2003), para a análise fatorial a amostra deve ser de quatro a cinco vezes maior que a quantidade de 
observações a serem analisadas. Portanto, para esse estudo uma amostra de pelo menos 165 respostas foi esperada e ultrapassada.

O estudo 1 sofreu limitações em sua amostra, uma vez que foi usada uma amostragem por conveniência. O estudo 2, por sua vez, sofreu limitações uma vez que os participantes foram abordados somente pela Internet, logo não alcançaram aqueles que não fossem usuários da rede mundial de computadores.

Além disso, o perfil dos usuários do Orkut - principal meio de divulgação do questionário - é limitado, uma vez que não se pode afirmar que engloba toda a população da região metropolitana do Rio de Janeiro, o que consequentemente não permitiu uma amostra totalmente aleatória. Inclusive, a única restrição para responder o questionário era que fosse um morador dessa região, não levando em consideração aqueles que já conheciam São Paulo ou a renda dos mesmos.

Outra limitação diz respeito ao próprio modelo de mensuração da imagem por meio da decomposição de seus atributos. Para Keller (1999), o nível de imagem não pode ser avaliado apenas pela medição de seus atributos, mas deve incluir também uma medição das percepções dos consumidores dos valores e benefícios alcançados ao usar a marca. Além disso, os dados do estudo estão baseados nas informações fornecidas por visitantes potenciais do destino. Não foi levantada a opinião dos responsáveis por gerenciar a imagem da cidade de São Paulo, no caso a Prefeitura Municipal da cidade de São Paulo.

\subsection{Tratamento dos Dados}

No estudo 1, de caráter qualitativo, o que se pretendeu avaliar foi o conteúdo das respostas. Para isso, foi feita uma tabela de frequência com os dados encontrados na free elicitation.

No estudo 2, de caráter quantitativo, os dados foram tratados com a ajuda do software SPSS 12.0 por meio de uma análise fatorial. Com a análise fatorial, buscou-se atingir o primeiro objetivo deste trabalho, que é o de encontrar os atributos que compõem a imagem da cidade de São Paulo percebida pelo público jovem da Região Metropolitana do Rio de Janeiro. O objetivo da análise fatorial é condensar a informação contida em um número original de 
variáveis em um conjunto menor, composto por fatores, com uma perda mínima de informação.

O primeiro passo da análise fatorial foi determinar se a amostra utilizada era adequada. Por isso, foram conduzidos o teste de Kaiser-Meyer-Olkin (KMO) e o Bartlett's test of Sphericity. O KMO compara as magnitudes dos coeficientes de correlação observados com os coeficientes de correlação parciais. A medida do KMO deve ser maior que 0,5 para que proceda uma análise fatorial satisfatória (FOULGER, 2004). O Bartlett's test of Sphericity é usado para testar a hipótese nula de que as variáveis na matriz de correlação da população não são correlacionadas. O nível de significância deve ser baixo o suficiente para rejeitar a hipótese nula e indicar que a relação entre as variáveis é forte (FOULGER, 2004).

A análise fatorial foi feita por meio do método de componentes principais para extração dos fatores por este ser o procedimento mais comum nas aplicações de marketing (HAIR et al., 1998). Para a extração de fatores, foi adotado o critério conservador de se considerar apenas os fatores com "raízes latentes" (eigenvalues) superiores a 1,0. Esse critério determina o número de fatores gerados.

O segundo passo da análise fatorial foi a rotação dos fatores. A rotação simplifica a estrutura dos fatores, facilitando a sua interpretação (HAIR et all, 1998). A rotação foi feita com o método Varimax. Este método força as cargas fatoriais a ficarem próximas de 0 ou 1 , obtendo cargas mais interpretáveis (HAIR et al., 1998). O efeito final de rotar a matriz de fatores é redistribuir a variância, de forma a obter um padrão de fatores mais simples.

Após a rotação dos fatores, é necessário interpretar os factor loadings, ou cargas fatoriais, que explicam a correlação entre a variável original e os fatores gerados pela análise fatorial.

Os fatores extraídos foram submetidos ainda à análise de confiabilidade, utilizando o coeficiente alfa de Cronbach. O coeficiente alfa é a estatística básica para determinar a confiabilidade de uma escala de medida com múltiplos itens, com base em sua consistência interna que garante a homogeneidade de um conjunto de itens (CHURCHILL, 1979). Hair et al. (1998) consideram um valor entre 0,6 e 0,7 como o limite mínimo de aceitação da confiabilidade da escala. 


\section{Resultados}

Os resultados desta pesquisa não reproduzem a opinião do universo de moradores jovens da região Metropolitana do Rio de Janeiro, mas podem apresentar uma tendência de opiniões desta população, com informações importantes para aqueles que gerenciam a imagem da cidade de São Paulo.

\subsection{Resultados do estudo 1}

A seguir são mostrados os resultados dos dois procedimentos usados na realização do estudo 1, feito com a resposta de 64 moradores da Região Metropolitana do Rio de Janeiro no mês de setembro de 2007.

\subsubsection{Resultado da análise de conteúdo}

Os itens a seguir foram encontrados a partir da análise de conteúdo de material promocional da cidade de São Paulo.

1. Patrimônio Histórico

3. Cultura e Arte

5. Gastronomia diversificada

7. Arquitetura

9. Eventos, Feiras e Exposições

11. Sofisticação

13. Compras
2. Vida noturna

4. Oportunidades para negócios/ trabalho

6. Roteiros temáticos

8. Desenvolvimento

10. Esporte - Fórmula 1

12. Religiosidade

14. Parques temáticos

15. Cidade grande e cosmopolita - "São Paulo, cidade mundo"

Com a observação dos itens encontrados, percebe-se que o destino cidade de São Paulo tem um foco bastante amplo, uma vez que ao mesmo tempo incentiva o turismo nos segmentos de 
lazer, de negócios, religioso e esportivo. A amplitude do foco está clara com o item 15, que visa apresentar uma cidade grande e cosmopolita. Neste mesmo sentido, a SP TURIS usa nos folhetos explicativos sobre a cidade a seguinte frase para chamar a atenção para a leitura do material promocional: "As muitas atrações da cidade mundo que funciona 24 horas.”

Vale ressaltar que não foi identificado nenhum símbolo específico usado na divulgação da cidade.

\subsubsection{Resultado da free elicitation}

O segundo procedimento para gerar a lista de atributos do estudo 2 foi a free elicitation. Neste procedimento, a única restrição feita para responder a pergunta "Quais são as três primeiras palavras ou expressões que vêm à sua mente quando você pensa na cidade de São Paulo?” era que os participantes morassem na Região Metropolitana do Rio de Janeiro. Embora não existisse a restrição para a faixa etária da amostra quando a pesquisa foi efetuada, a totalidade dos participantes possuía de 20 a 29 anos. Os resultados são apresentados na tabela 1 .

O único atrativo turístico lembrado na free elicitation foi a Avenida Paulista, citada por apenas uma pessoa.

Tabela 1 - Resultado da free elicitation

\begin{tabular}{|l|c|l|l|c|}
\hline Itens avaliados & Frequência & & Itens avaliados & Frequência \\
\hline $\begin{array}{l}\text { Congestionamento/ } \\
\text { engarrafamento/rodízio de } \\
\text { carros/ trânsito intenso/ faróis }\end{array}$ & 35 & & Multidão & 2 \\
\hline Poluição & 31 & & Gírias & 2 \\
\hline $\begin{array}{l}\text { Trabalho/ dinheiro/ negócios/ } \\
\text { carreira }\end{array}$ & 22 & Desigualdade & 1 \\
\hline Cultura/ museus & 13 & & Congonhas & 1 \\
\hline Violência & 11 & & Av. Paulista & 1 \\
\hline Noite/ balada & 11 & Organização & 1 \\
\hline Restaurantes & 10 & Suja & 1 \\
\hline $\begin{array}{l}\text { Maior cidade do país/ principal } \\
\text { capital / megalópole/ cidade } \\
\text { grande/ metrópole }\end{array}$ & 8 & Tietê & 1 \\
\hline Caótico/ caos urbano & 8 & & 1 \\
\hline \begin{tabular}{l} 
Desenvolvimento/ economia \\
\hline
\end{tabular} & 7 & & PCC & 1 \\
\hline
\end{tabular}




\begin{tabular}{|l|l|l|l|l|}
\hline Povo sério e frio & 6 & & Indiferença & 1 \\
\hline Diversos prédios/ cinza & 5 & & Esporte & 1 \\
\hline Terra da garoa & 3 & & Enchentes & 1 \\
\hline Tempo nublado - frio & 3 & Indústria & 1 \\
\hline Compras & 2 & & Agito & 1 \\
\hline
\end{tabular}

Fonte: Elaboração própria

\subsection{Resultado do estudo 2}

A amostra do estudo 2 foi representada por $49 \%$ de respondentes do sexo masculino e $51 \%$ do sexo feminino com $64 \%$ concentrada na faixa etária entre 20 e 29 anos e $8 \%$ na faixa entre 15 e 19 anos. Somando as duas faixas etárias, chegamos a 72\% dos respondentes, mostrando assim, predominância de uma população jovem. Sobre a cidade de residência, $47 \%$ eram moradores no Rio e Janeiro, 32\% de Niterói e 12\% de São Gonçalo. Demais cidades tiveram pequena expressão.

\subsubsection{Análise dos dados}

O teste de KMO do estudo teve resultado de 0,840 e o Bartlett's test of Sphericity obteve significância de 0,000 (tabela 2) a partir dos quais é confirmada a adequação da amostra para a realização da análise fatorial.

Tabela 2 - KMO e Bartlett's test of Sphericity

\begin{tabular}{|c|c|c|}
\hline \multicolumn{2}{|c|}{ Kaiser-Meyer-Olkin Measure of Sampling Adequacy. } &, 840 \\
\hline \multirow{2}{|c|}{$\begin{array}{c}\text { Bartlett's Test of } \\
\text { Sphericity }\end{array}$} & Approx. Chi-Square & 3557,765 \\
\cline { 2 - 3 } & DF & 528 \\
\cline { 2 - 3 } & Sig. &, 000 \\
\hline
\end{tabular}

Fonte: SPSS, 12.0

Após a verificação da adequação da amostra, foi feita a análise fatorial que gerou 7 fatores com $62,469 \%$ de variância. Os atributos da imagem foram posicionados no fator cujo factor loading teve a mais alta correlação com o fator (tabela 3). 
Tabela 3 - Matriz rotacionada dos componentes

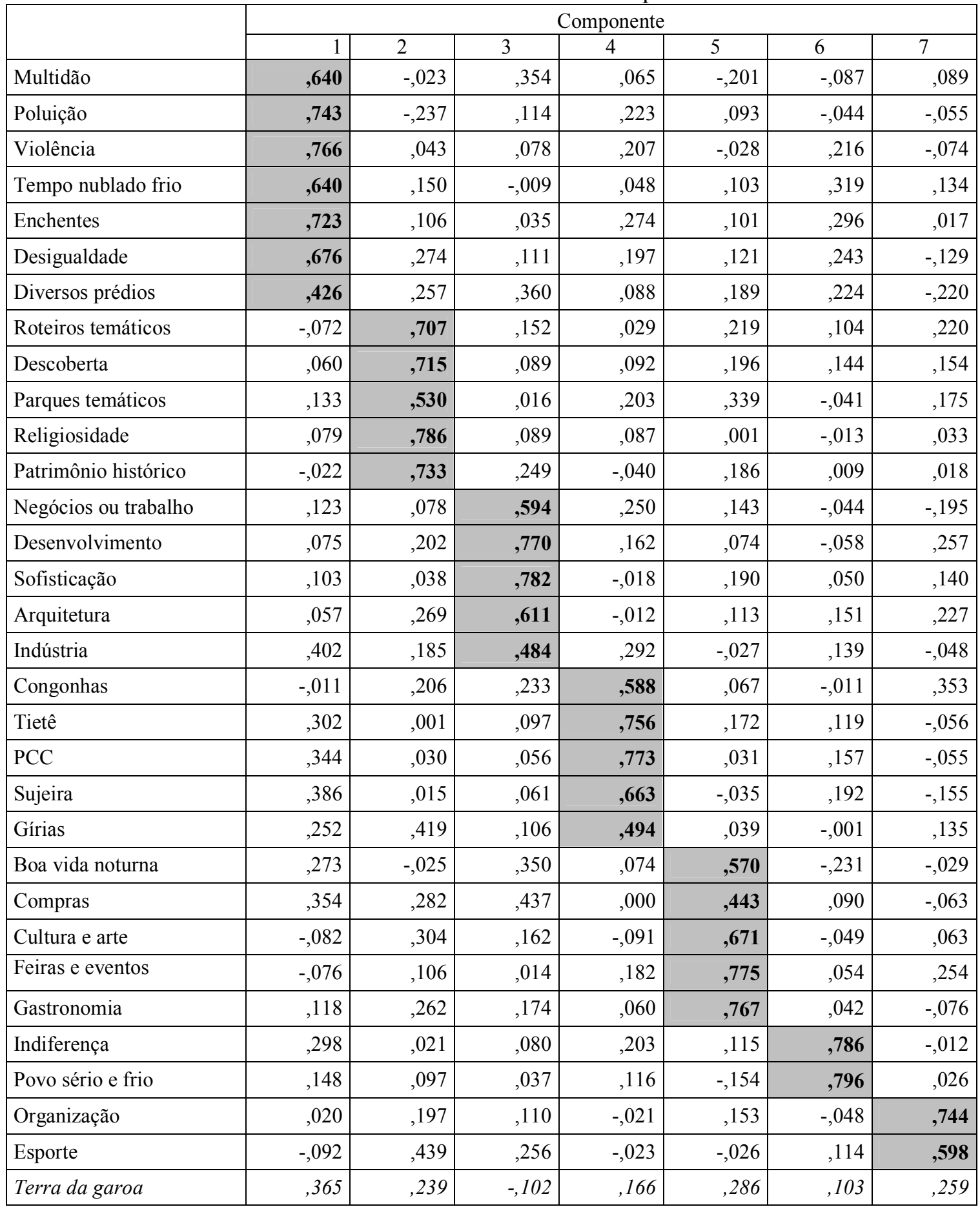

Extraction Method: Principal Component Analysis.

Rotation Method: Varimax with Kaiser Normalization.

Fonte: SPSS, 12.0 
Os sete fatores extraídos foram nomeados da seguinte forma:

1- São Paulo cidade grande: com características típicas de qualquer metrópole, como congestionamento, multidão, poluição, violência, desigualdade. O fator pode ser influenciado pelo fato de a cidade ser percebida como uma cidade cosmopolita, que tem um pouco de tudo que existe no mundo, como visto pelos dados da análise de conteúdo. O que difere neste fator é que também estão nele os atributos tempo nublado e frio e enchentes, o que significa que o clima, para os respondentes, tem o mesmo peso dos outros atributos que caracterizam São Paulo como uma metrópole.

2- São Paulo patrimônio e lazer: nesse fator combinam-se os atributos que proporcionam descontração e relaxamento ao público, como parques temáticos e roteiros temáticos como os que estão voltados ao patrimônio da cidade, que por sua vez está ligado à religiosidade, devido ao fato de que parte do patrimônio da São Paulo está dentro das igrejas e dos mosteiros. O atributo descoberta relaciona-se aos outros por incitar o conhecimento desse patrimônio e dos lugares próprios para o lazer.

3- São Paulo desenvolvimento: neste fator estão os atributos negócios, desenvolvimento, sofisticação, arquitetura e indústria. Esses atributos destacam o lado econômico da cidade, como uma das cidades mais ricas do Brasil, geradora em emprego e renda. A arquitetura pode estar incluída nesse fator como forma de ostentar a modernidade da cidade, como, por exemplo, o edifício Copan projetado por Oscar Niemeyer.

4- São Paulo pontos críticos: reúne gírias, Congonhas, Tietê, PCC e sujeira. O PCC é uma facção criminosa que existe em São Paulo. Congonhas pode ser lembrado pelo problema do caos aéreo que viveu o país no ano de 2007 e principalmente porque a pesquisa foi feita logo após a um grande acidente com um avião da companhia aérea TAM nesse aeroporto. A poluição do rio Tietê, muito divulgada na mídia, acaba por se relacionar com o atributo sujeira. Uma vez que o construto gírias teve carga fatorial semelhante a dos demais construtos do fator, que inclui atributos como sujeira, podemos inferir que é um construto que merece futuras investigações. 
5- São Paulo consumo: esse fator trata de boa vida noturna, compras, feiras e eventos e cultura e arte. Em todos os atributos, de certa forma está envolvida a questão do consumo. Compras é o mais claro deles, porém o consumo também está envolvido nas feiras e eventos, cujo objetivo muitas vezes é o de incentivar o consumo, com o lançamento de produtos e tendências. O incentivo ao consumo acontece também nas casas noturnas e boates da cidade. Observa-se ainda o consumo da cultura em si, presente nos diversos atrativos culturais que estão ao alcance do visitante.

6- São Paulo povo: neste fator estão indiferença e povo sério e frio. Como os próprios atributos já indicam, os paulistanos são visto pelos respondentes de maneira pejorativa. Turistas podem ser estimulados a conhecer um destino de forma a interagir com as pessoas que moram nele, mas se tomarmos o atributo indiferença como sinônimo de apatia relacionada ao povo da cidade, podemos inferir que esse atributo não contribui para a atração de turistas para o destino.

7- São Paulo organização: neste fator estão organização e esporte. O esporte se associa à organização da cidade, talvez por sediar grandes eventos de sucesso, como o Grande Prêmio de Fórmula 1, em Interlagos. Vale lembrar que dos atrativos turísticos lembrados pelos respondentes, está também o estádio do Morumbi, a ser apresentado na tabela 4.

O atributo terra da garoa foi retirado da análise por não apresentar cargas significativas em nenhum fator. Segundo Hair et al. (1998), em uma amostra de 200 pessoas, a carga fatorial mínima que cada atributo deve ter para ser considerado na análise fatorial é de ,40. Como a carga fatorial mínima não foi atingida, o item foi retirado da escala.

Após feita a análise fatorial, testou-se a confiabilidade dos dados. O Alfa de Cronbach gerou valores satisfatórios para todos os fatores, como a seguir:

São Paulo Cidade grande: $\quad 0,855$

São Paulo Patrimônio e lazer: $\quad 0,821$

São Paulo Desenvolvimento: $\quad 0,771$ 
São Paulo Pontos críticos: $\quad 0,795$

São Paulo Consumo: $\quad 0,696$

São Paulo Povo: $\quad 0,720$

São Paulo Organização: $\quad 0,625$

Os dados da figura 2 mostram a relação das médias dos fatores obtidos, com mediana de valor 3,0. A análise da figura permite verificar que o fator mais significante foi o São Paulo Cidade Grande com maior média - 4,2, o que significa dizer que os participantes concordam com essa imagem da cidade. Logo atrás, estão os fatores São Paulo Consumo, com média 4,1, e São Paulo Desenvolvimento, com média 3,9, que mostram que nessas questões a imagem da cidade é percebida de acordo com que esta visa ser transmitida, se compararmos com os dados da análise de conteúdo. No que foi apresentado na análise de conteúdo, esses são pontos que a cidade se empenhada em divulgar. Após, está o fator São Paulo Crítico, o que demonstra que os pesquisados concordam com a imagem de que a cidade possui diversos pontos críticos como sujeira e PCC, que é uma facção criminosa atuante na cidade. A partir desses dados, percebe-se que a cidade requer um maior esforço para corrigir sua imagem negativa. A seguir, está o fator São Paulo Povo sério, com média 3,5, demonstrando que parte significativa da amostra também concorda com essa imagem da cidade.

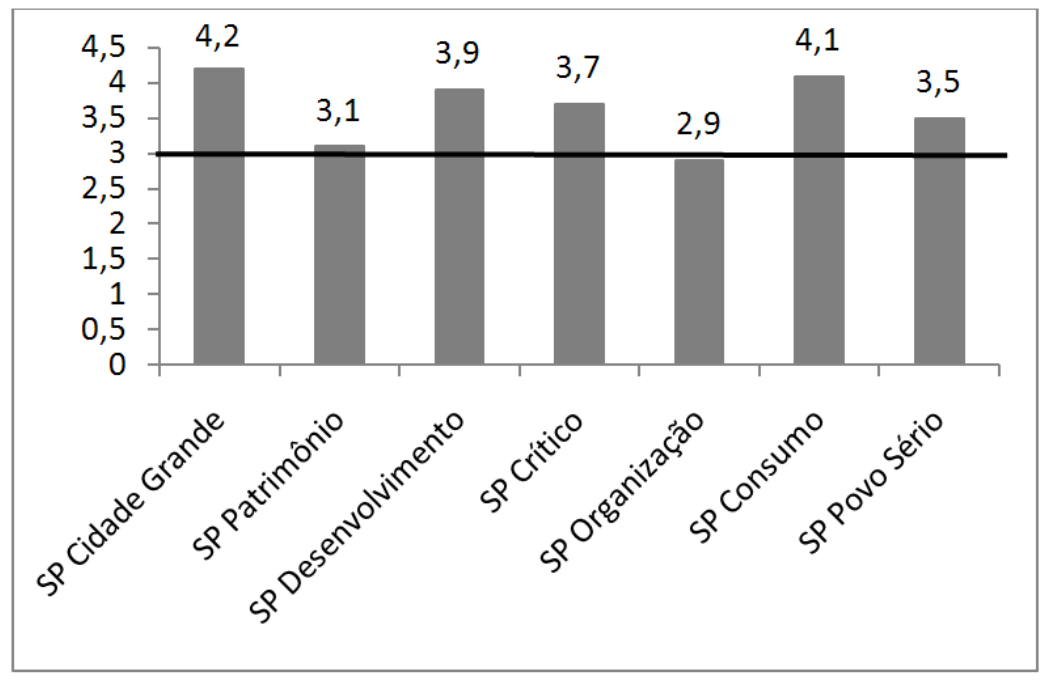

Figura 2 - Médias dos fatores 
Os fatores São Paulo Patrimônio e Lazer e São Paulo Organização apresentaram médias mais próximas à mediana, o que na escala de 5 pontos de Likert, variando de plena discordância e plena concordância, corresponde à posição do continuum de não concordância e também não discordância sobre essas imagens para a cidade de São Paulo.

Em contrapartida, também foi feita a análise dos atrativos turísticos lembrados pelos respondentes. Mais de uma resposta era permitida. Os resultados encontram-se na tabela 4.

Tabela 4 - Atrativos turísticos da cidade de São Paulo

\begin{tabular}{|l|l|l|l|}
\hline Atrativo Turístico & Frequência & Atrativo Turístico & Frequência \\
\hline Parque do Ibirapuera & 40 & Viaduto do Chá & 3 \\
\hline MASP & 31 & Mercado Municipal & 3 \\
\hline Avenida Paulista & 14 & Pátio do Colégio & 2 \\
\hline Catedral da Sé & 10 & Pinacoteca & 2 \\
\hline Bairro da Liberdade & 9 & Parada Gay & 2 \\
\hline Museu da Língua Portuguesa & 8 & Zoológico & 2 \\
\hline Autódromo de Interlagos & 7 & $\begin{array}{l}\text { Monumento } \\
\text { Bandeirantes }\end{array}$ & 1 \\
\hline Estádio do Morumbi & 7 & Instituto Butantã & 1 \\
\hline Estação da Luz & 6 & Galeria do Rock & 1 \\
\hline Museu do Ipiranga & 6 & Sala São Paulo & 1 \\
\hline Rua 25 de Março & 5 & Bairro do Bexiga & 1 \\
\hline MAM & 4 & Nenhum & 37 \\
\hline Memorial da América Latina & 3 & & \\
\hline
\end{tabular}

Fonte: Elaboração própria

A partir da análise dos dados da tabela 4, percebe-se que o atrativo mais citado foi o Parque do Ibirapuera, seguido do MASP.

Uma pessoa respondeu como atrativo turístico a Igreja de Nossa Senhora Aparecida, na cidade de Aparecida do Norte. Duas pessoas responderam como atrativo a praia de Guarujá. Ambos são atrativos que pertencem ao estado São Paulo, mas não se localizam na cidade da São Paulo.

Dos pesquisados, 70 pessoas deram respostas vagas, como restaurantes, boates, teatros, 
compras, shows, feiras, eventos, shoppings, cafés, prédios e congressos, o que mostra que eles não se lembravam de nenhum atrativo específico da cidade. Não foram citados atrativos relevantes da cidade como o Solar da Marquesa, o Museu da Casa Brasileira e a Cinemateca. Pela observação da tabela 4, também é possível notar que alguns atrativos importantes tiveram pouca expressão, como o Pátio do Colégio, o Museu do Ipiranga, o Monumentos aos Bandeirantes, o Memorial da América Latina, a Sala São Paulo e a Estação da Luz. Das pessoas pesquisadas, 37 não se lembraram de nenhum atrativo turístico da cidade.

Por último, procurou-se saber os níveis de interesse e intenção do respondente em visitar a cidade de São Paulo (figuras 3 e 4). 
A figura 3 compara o interesse e a intenção em visitar a cidade de São Paulo. O procedimento estatístico assumiu valores para quantificar as variáveis. Sendo assim, 1 significou nenhum(a) interesse/intenção, 2 pouco (a) interesse/ intenção e 3 muito (a) interesse/intenção. Percebe-se que os dois resultados, interesse - 1,88 - e intenção - 1,83, ficaram abaixo da mediana 2 , o que demonstra pouca motivação por parte dos respondentes em visitar a cidade, mesmo com todo o potencial turístico que ela possui. Fazendo uma relação com os dados dos fatores gerados pela análise fatorial, a baixa motivação pode estar relacionada ao mau posicionamento da marca da cidade, com os respondentes percebendo-a principalmente com características de uma cidade grande, que são os fatores com resultados mais significantes da análise fatorial.

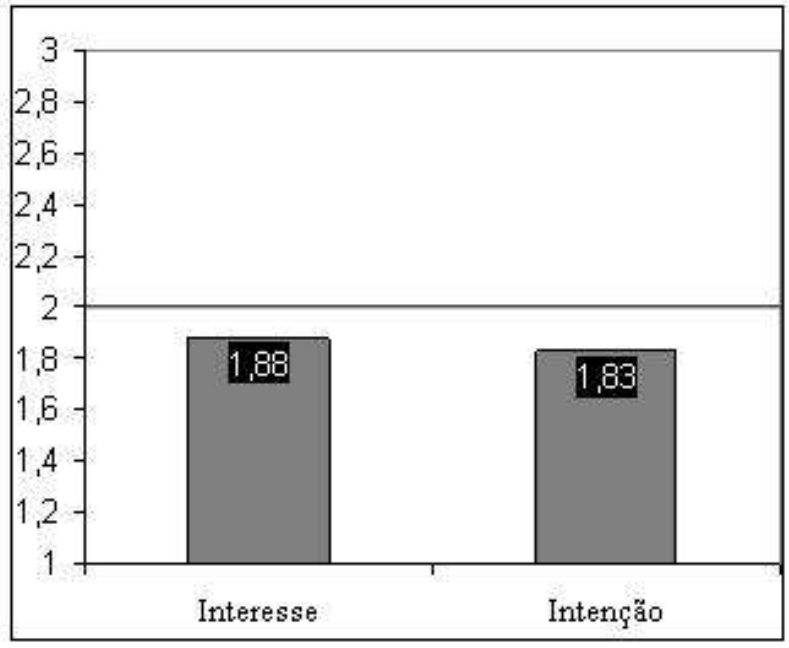

Figura 3 - Médias de interesse e intenção em visitar a cidade de São Paulo

A figura 4 apresenta mais detalhadamente os níveis de interesse e intenção em visitar a cidade. Dos pesquisados, apenas $18 \%$ dos respondentes possuem muito interesse e $19 \%$ muita intenção em visitar a cidade. 

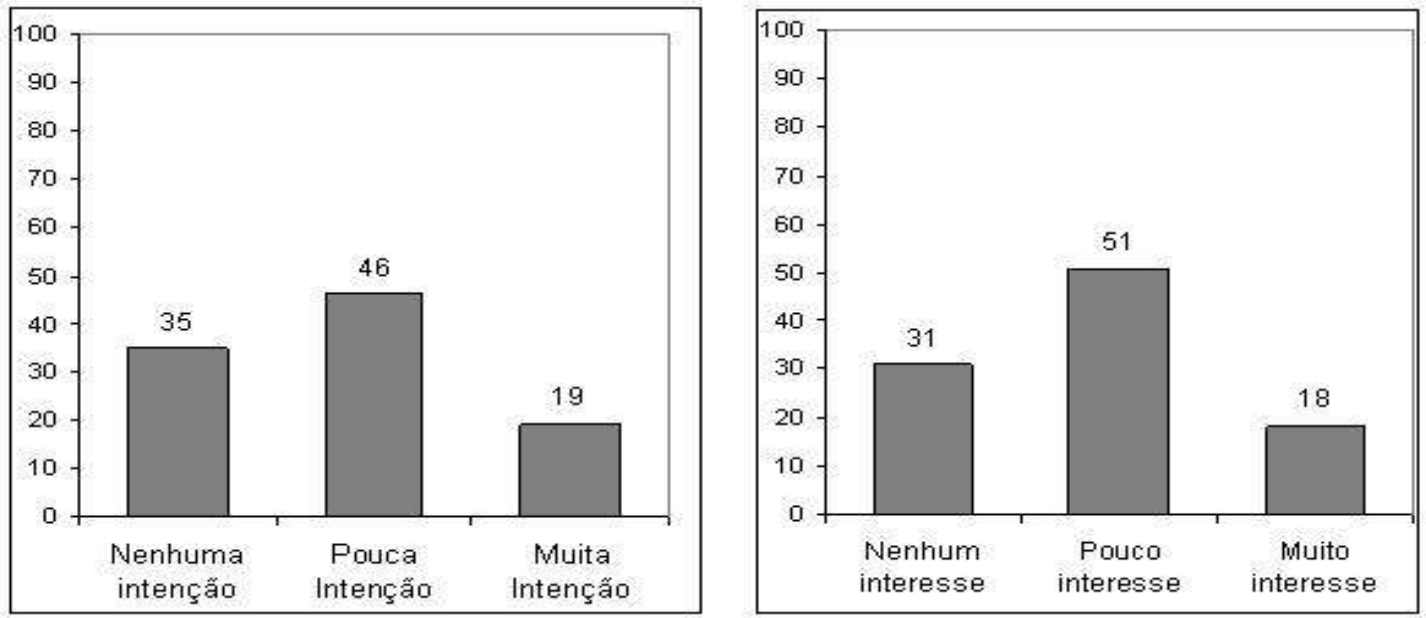

Figura 4 - Interesse em visitar a cidade de São Paulo

\section{Discussão dos Resultados}

Com o resultado da análise de conteúdo do estudo 1, foi vista a amplitude do foco na divulgação da cidade de São Paulo. Essa estratégia de promoção como um destino que oferece um pouco de tudo o que o turista deseja encontrar pode prejudicar o próprio processo de escolha do destino. Para Ituassu e Oliveira (2004), a decisão de ampliar o foco de produto, em vez de restringi-lo, é equivocada e deixa a decisão de compra do turista mais complexa.

A não identificação de um símbolo para a cidade também desfavorece a escolha deste destino pelos consumidores, uma vez que este seria um elemento de diferenciação de seus competidores.

Com uma comparação dos resultados da free elicitation e da análise de conteúdo percebe-se um conflito entre os dados de cada um. Por um lado, como era esperado, a análise de conteúdo de folhetos e sites oficiais da Prefeitura de São Paulo e de pacotes de operadoras que vendem o destino revelou características positivas sobre a cidade. Por outro lado, na free elicitation, muitos dos atributos encontrados revelam características negativas. Embora no modelo de Baloglu (1999) a formação da imagem do destino leve em consideração fatores pessoais, experiências anteriores e fontes de informação, ressaltamos no estudo as fontes de 
informação, sobretudo aquelas informações provenientes de material fornecido por profissionais do setor utilizadas na análise de conteúdo, pois são esses profissionais que intencionalmente trabalham a imagem da cidade especificamente como um destino turístico.

A partir da análise dos resultados do estudo 2, compreende-se que a cidade de São Paulo é bem sucedida em alguns aspectos ao transmitir sua imagem. Como na análise de conteúdo do estudo 1, esta visa transmitir a imagem de uma cidade grande e cosmopolita, desenvolvida e que possui várias opções de consumo. O estudo 2 comprova que a cidade é vista por essas imagens. Contudo, o que se pode perceber, com os demais dados do estudo 2, é que essas imagens não motivam os respondentes a conhecer a cidade, visto os baixos níveis de interesse e intenção em visitá-la. Ao mesmo tempo, essas imagens são pertinentes a outras metrópoles que, exatamente por terem a condição de metrópole, têm em comum grande circulação de mercadoria e renda e, por isso, são também desenvolvidas e possuem várias opções de consumo.

Por outro lado, há outras características da cidade encontradas nos resultados que não estão de acordo com o que a imagem que a cidade visa transmitir e que também prejudicam seu fluxo turístico. É o caso da visão de São Paulo como uma cidade com diversos pontos críticos, que não é lembrada por seu patrimônio e suas opções de lazer, com pouca organização e que tem um povo sério e frio. Em especial, o item patrimônio, se bem trabalhado com o público estudado, poderia ser um elemento motivador para a visitação da cidade, uma vez que esta possui obras e construções únicas e que não poderiam ser copiadas por outras cidades, como por exemplo o Pátio do Colégio, o Solar da Marquesa, a Sala São Paulo e o Museu do Ipiranga. Vale lembrar que esses atrativos tiveram pouca ou nenhuma expressão como atrativos da cidade lembrados pelos respondentes.

\section{Considerações Finais}

O presente trabalho teve dois objetivos: o de compreender como o público jovem da Região Metropolitana do Rio de Janeiro percebe a imagem do destino cidade de São Paulo; e o de verificar a influência potencial da imagem percebida na intenção de visitar o destino estudado. 
Para atingir esses objetivos, foram conduzidos dois estudos que usaram uma combinação de metodologias estruturadas e não-estruturadas.

Os resultados do estudo 1 mostraram que existe um conflito entre a imagem que a cidade visa transmitir e aquela percebida pelo público em questão. Os do estudo 2 indicaram que a cidade é percebida por sete fatores, gerados a partir da análise fatorial, a saber: São Paulo cidade grande, São Paulo patrimônio e lazer, São Paulo desenvolvimento, São Paulo pontos críticos, São Paulo consumo, São Paulo povo e São Paulo organização. Além disso, foram constatados baixos níveis de interesse e intenção dos respondentes em visitá-la.

A importância da imagem na diferenciação e consequente escolha do turista por um determinado destino é ponto pacífico na literatura existente sobre marketing turístico. No caso do município de São Paulo, ao ser analisado o resultado da análise de conteúdo do estudo 1, percebe-se a amplitude do foco da divulgação do produto. Com o que foi visto na revisão de literatura, o foco do produto deve ser restrito de forma a simplificar a escolha de um destino. Por isso, recomenda-se que a estratégia de promoção adotada pelos órgãos que gerenciam a imagem da cidade de São Paulo seja revista. Sugere-se, no caso do município de São Paulo, que haja uma maior segmentação dos públicos-alvos da cidade, ao invés de tentar atingir ao mesmo tempo vários públicos distintos. Também é importante notar que grande parte da amostra deste estudo foi constituída por jovens. Logo, é conveniente um melhor trabalho de imagem com o público estudado, pois este poderá representar os visitantes da cidade no futuro.

O estudo 2 também ressalta o mau posicionamento da imagem da cidade. Dos fatores extraídos dos atributos que compõem a imagem do destino em questão, o que obteve maior média foi o fator relacionado às características de São Paulo como uma cidade grande, como multidão, poluição, violência e desigualdade, o que se deve ao fato de São Paulo ser uma cidade grande e cosmopolita. Como essas características são comuns a demais metrópoles, isto faz com que a cidade da São Paulo não se diferencie das outras. Além disso, essas características da cidade criam uma imagem desfavorável da mesma, prejudicando sua escolha como um destino turístico, pois os turistas buscam viver boas experiências de viagens. Como no estudo de Lee, Cai e O'Leary (2005), para que a mensagem transmitida ao 
público seja eficiente, é preciso que ela contenha proposições únicas de venda, que informem os consumidores sobre benefícios genuínos e únicos do produto. A cidade em estudo enfatiza atributos que não são únicos do lugar e que, exatamente por isso, não são suficientes para lhe conferir um diferencial competitivo.

Os dados encontrados sobre os atrativos da cidade de São Paulo no estudo 2 mostram que parte dos pesquisados ou não os conhece ou conhece pouco, o que vem a interferir na escolha deste município como destino para férias. A partir dos dados é possível refletir sobre a influência das fontes de informação no processo de escolha de um destino. Se um turista potencial não tiver a devida informação sobre um destino, ele não poderá se interessar em visitá-lo. A falta de informação, por consequência, interfere na intenção e interesse em visitar a cidade, o que foi percebido com os dados que mostram baixos níveis de interesse e intenção por parte dos pesquisados em visitar a cidade de São Paulo.

Para pesquisas futuras, recomenda-se a repetição deste estudo para analisar se houve mudanças na transmissão e percepção da imagem da São Paulo pelo público da região Metropolitana do Rio de Janeiro, bem como a partir da visão de outros públicos relevantes para o fluxo turístico da cidade de São Paulo. É interessante ainda que a mesma pesquisa possa ser feita com o objetivo de analisar a imagem de outros destinos turísticos importantes no Brasil e no exterior.

\section{Referências}

AAKER, Jennifer. 1997. Dimensions of brand personality. Journal of Marketing Research, v. 34, n. 3, p. 342-352.

BALOGLU, Seyhmus; McCLEARY, Ken W. 1999. A model of destination image formation. Annals of Tourism Research, v. 25, n. 4, p. $868-897$.

BEERLI; Asunción; MARTÍN, Josefa D. 2004. Factors influencing destination image. Annals of Tourism Research, v. 31, n.3, p. $657-681$.

CHURCHILL, JR, Gilbert A. 1979. Marketing research: methodological foundations, 7 ed. Fort Worth: Dryden. 
COLLIS, J; HUSSEY, Roger. 2005. Pesquisa em administração: um guia prático para alunos de graduação e pós-graduação. Porto Alegre: Bookman.

ECHTNER, Charlotte M.; RITCHIE, J. R. Brent. 1991. The meaning and measurement of destination image. The Journal of Tourism Studies, v. 2, n. 2, p. 2 -12, dez.

2003 The meaning and measurement of destination image. The Journal of Tourism Studies, v. 14 , n. 1 , p. $37-48$, maio.

FOULGER, D. and other participants. 2004. Statistical methods. Disponível em: $<$ http://evolutionarymedia.com/wiki.htm?StatisticalMethods>. Acesso em 21 abr. 2008

HAIR, Joseph F. Junior; ANDERSON, Rolph E.; TATHAM, Ronald L.; BLACK, Willian C. 1998. Multivariate data analysis. 5. ed. New Jersey: Prentice Hall.

IBGE. 2006. Região Metropolitana do Rio de Janeiro. Disponível em: <ftp://geoftp.ibge.gov.br/Organizacao/_Divisao_Territorial/2007/ Acesso em 18 maio 2008.

ITUASSU, Cristiana Trindade; OLIVEIRA, Maria Regina de Carvalho Teixeira. 2004. Destino Brasil: uma análise da campanha publicitária realizada pela EMBRATUR e de sua contribuição para a formação da imagem do país. XXVIII Encontro da ANPAD, Curitiba.

KELLER, Kevin Lane. 1999. Measuring brand power: validating a model for optimizing brand equity. Journal of Product e Brand Management, v. 8, n. 3, p. $170-184$.

KELLER, Kevin. 1993. Conceptualizing, measuring, and managing customer-based brand equity. Journal of Marketing, v. 57, Jan.

KOTLER, Philip; ARMSTRONG, G. 1998. Princípios de marketing. Rio de Janeiro: Prentice Hall.

; GERTNER, David. 2002. Country as brand, product and beyond: a place marketing and brand management perspective. Journal of Brand Management, v. 9, n. 45, p. 259 - 261, abr.

LEAL, Sérgio Rodrigues. 2006. Imagens de destinações turísticas: uma análise crítica do material promocional da prefeitura da cidade de Recife. Turismo em Análise, v. 17, n. especial, p. 36 - 55, jan.

LEE, Gyehee; CAI, Liping A., O’LEARY, Joseph T. 2005. www.Branding.States.US: an analysis of brand-building elements in the US state tourism websites. Tourism Management, n. 27, p. 815 - 828, maio.

MIDDLETON, Victor T. C. 2002. Marketing de turismo. Rio de Janeiro: Campus.

O'LEARY, Sinéad; DEEGAN, Jim. 2005. Ireland's image as a tourism destination in France: attribute importance and performance. Journal of Travel Research, v.43, p. 247- 256, fev.

OLIVEIRA, Rodrigo Bomfim. 2006. A "comunidade imaginada" Bahia e a publicidade da Bahiatursa: um enfoque sobre o estereótipo da preguiça. Caderno Virtual de Turismo, v.6, n.3, p. 5463.

PÉREZ-NEBRA, Amália Raquel. 2005. Medindo a imagem do destino turístico. 107f. Dissertação de Mestrado em Psicologia, Universidade de Brasília, Brasília. 
PREFEITURA DE SÃO PAULO. 2006. Listagem de Bens Tombados pelo IPHAN na cidade de São Paulo. Disponível em: <http://www.prefeitura.sp.gov.br/cidade/upload/f4590_Lista_Bens_IPHANSP.pdf>. Acesso em 18 mar. 2008.

REZENDE-PARKER, Aline M; MORRISON, Alastair M.; ISMAIL, Joseph A. 2003. Dazed and confused? An exploratory study of the image of Brazil as a travel destination. Journal of Vacation Marketing, v.9, n.3, p. $243-259$, jun.

RICHARDSON, J; COHEN, J. 1993. State slogans: the case of the missing USP. Journal of Travel \& Tourism Marketing, v. 2, n. 1, p. 91-109.

RUSCHMANN, Doris. 2001. Marketing turístico: um enfoque promocional. 7 ed. Campinas: Papirus.

SPTURIS. 2006. Pontos turísticos da cidade de São Paulo. São Paulo Turismo S/A. Disponível em: $<$ http://www.cidadedesaopaulo.com/eventos/acontece.asp>. Acesso em 18 mar. 2008.

UM, S., CROMPTON, J. 1990. Attitude determinants in tourism destination choice. Annals of Tourism Research, v. 17, n. 3, p. 432-448.

WOODSIDE, A. G., LYSONSKI, S. 1989. A general model of traveler destination choice. Journal of Travel Research, v. 27, n. 4, p. 8-14.

ZOTTIS, Alexandra Marcella. 2004. A contribuição da festa da uva à imagem turística de Caxias do Sul - O Olhar dos Cartazes. In_: Congresso Brasileiro de Ciências da Comunicação, 27, Porto Alegre, 2004. Disponível em: <http://reposcom.portcom.intercom.org.br/dspace/bitstream/1904/ 18329/1/R0542-1.pdf>. Acesso em 13 jul. 2007.

Recebido em: 17/01/2010 ( $1^{\mathrm{a}}$ versão) $02 / 08 / 2010$ ( $2^{\mathrm{a}}$ versão)

Aprovado em: 25/10/2010 